\title{
Influences of the Residential Environment on the Apartment Remodeling: Involving the Expansion of Households and Dwelling Area
}

\author{
Ji-Eun Lee ${ }^{1}$ and Young-Ho Yoon ${ }^{2}$ \\ (Received March 28, 2011 / Revised April 20, 2011 / Accepted April 25, 2011)
}

\begin{abstract}
Space extension and the increase of the number of households are helpful to raise business value of the remodeling through the renovation of apartment houses that is required by residents of new cities and large-scaled apartment. However, in the case of accepting this demand, it could have a bad influence on the landscape of a complex in terms of the structure of apartment houses and the safety of construction and urban planning, and a problem occurs in the aspect of fairness for reconstruction. For the study, the current status related to the remodeling system through laws, related articles since 2000 and research data was analyzed. In addition, the individual quantitative analysis was conducted in the four aspects to judge whether households expansion for remodeling is plausible:1) Statistical data to comprehend the changes of population and social structure 2) Survey data of floor space index and the building-to-land ratio of new cities at the intial stage for the review of the effect of architectural planning and urban environment 3) Surveys of experts on structural safety in order to judge whether the demand of expansion is accepted or not. 4) Quantitative analysis of each item to compare fairness with reconstruction. Therefore, this study is intended to understand problems of the remodeling system that is currently operated. Moreover, it will be further reviewed that the expansion of households is feasible through the permission of expansion and it will be discussed that the revitalization of the apartment remodeling has a positive impact on the residential environment.
\end{abstract}

Key words Apartment Remodeling, Space Extension, the Number of Households, Residential Environment

\section{Introduction}

\subsection{Purpose}

Since the expansion and the increase of the number of households through the remodeling ${ }^{1)}$ of apartment houses that was raised by residents in a new town and large-scaled apartment are helpful to raise business value of the renovation, residents want to secure the new sales through the expansion of households and to freely change the plane structure by households.

The introduction of system such as vertical expansion of the top floor, the horizontal expansion of side connection, the expansion of a separate building like a new construction within a complex, the integration of households by demolishing bearing walls as types of households expansion is continuously demanded but in the case of accepting these demands, it is necessary to review this since it could have a great influence on the landscape of a complex in terms of the safety of structure construction of apartment houses and urban planning.

In the case that the additional vertical expansion of a few floors on the top floor of the existing structure that was designed without considering expansion during new construction is permitted, it can't help raising a question about the possibility of securing the structural safety of the building. Besides, further review on the expanded households is required since there is a concern that general sales generated by the expansion of households in apartment houses might degenerate into simply a method to increase personal assets by distorting the essence of the renovation. The standpoint of construction companies and the public toward the renovation in the country has an aspect of recognizing it as a new project to alternate the reconstruction and responding to it, it's time to convert the recognition to consider the displacement of construction wastes the and to be able to review it as an alternative to reduce the pollution of environment resulting from construction by making use of the original purpose

This study is a part of results of "The Study of Feasibility of Households Expansion by Remodeling of Apartment Houses", which was a commissioned project by the Ministry of Land, Transport and Maritime Affairs in 2010.

1) Associate Research Fellow, Land \& Housing Institute (Main author: jee@lh.or.kr)

2) Executive Research Fellow, Land \& Housing Institute (Correspondiong author: yhyoon@lh.or.kr) 
of the renovation as a sustainable construction method.

Therefore, this study is intended to understand problems of the remodeling system that is currently operated. Moreover, it will be further reviewed that the expansion of households is feasible through the permission of expansion and it will be discussed that the revitalization of the apartment remodeling has a positive impact on the residential environment.

\subsection{Method and Procedure}

The scope of analysis of the judicial system related to the remodeling was from the year of 2001 when provisions related with the remodeling were made up to the present. The spacial scope for the review of the operational status of the system and the feasibility of households expansion was limited to apartment houses and to those that are the subjects of remodeling as of now.

For the method of study, the current status related to the remodeling system through laws related to the remodeling, related articles since 2000 and research data etc. was analyzed, and the individual quantitative analysis was conducted in the four aspects to judge whether households expansion for remodeling is plausible.

1) Statistical data to comprehend the changes of population and social structure

2) Survey data of floor space index and the building-to-land ratio of new cities at the intial stage for the review of the effect of architectural planning and urban environment

3) Surveys of experts on structural safety in order to judge whether the demand of expansion is accepted or not.

4) Quantitative analysis of each item to compare fairness with reconstruction

The reasonable policy suggestion direction was deduced through consultation with related companies and experts on these results.

\section{Study of Remodeling System of Apartment Houses}

\subsection{Study of Domestic Remodeling System of Apartment Houses}

The laws related to remodeling are distributed into ${ }^{\circledR}$ Law of Construction $\_,{ }^{『}$ Law of Housing $₫,{ }^{『}$ City and Residential Environment Renewal Development Act $₫$. There are lots of demands for the special law for unification of laws related with remodeling but there is a positive aspect that separate management in the law of general buildings and in the individual law related with apartment houses can promote the continuos development of a system as well.

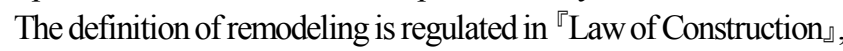
${ }^{\circledR}$ Law of Housing $』$ and remodeling is defined as "major repair or

1) 'Remodeling' in building codes of Korea means a change in structure or volume in building codes of Korea. The term in standards varies with countries: Reform in Japan, Upgrading in Singapore, Remodeling in the United States, Renovation in the United Kingdom, Modernization in France and Germany

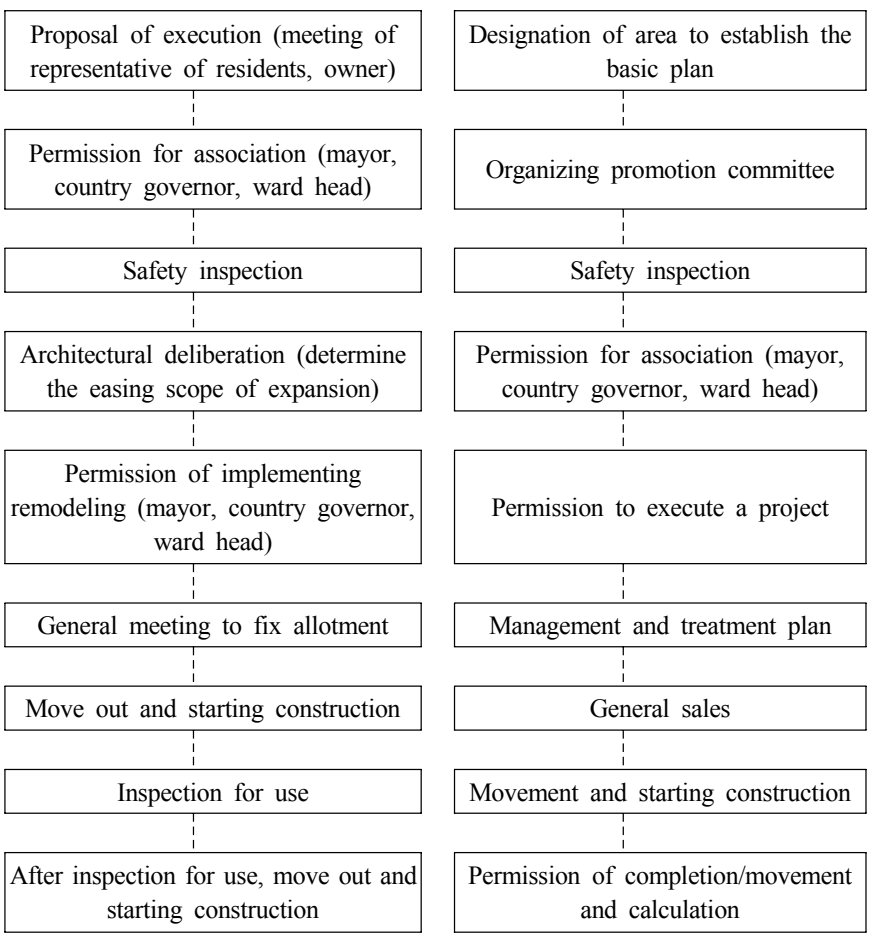

Fig. 1. Comparison between remodeling and the procedure of reconstruction project

expansion to restrain deterioration of a building or to improve its function etc."2). The permitted term for remodeling of apartment houses is 15 years and the expansion is permitted within three 10 th of area only for residence 3 ) and piloti structure is accepted and one floor expansion on the top floor is permitted.

However, since it's impossible to increase and reduce the number of households through remodeling under current law, there is restriction on the change of the number of households and the necessity for improvement of the system is much pointed out for this part.

Compared remodeling of apartment houses with the law related with reconstruction, remodeling applies ${ }^{\circledR}$ Law of Housing and reconstruction applies ${ }^{『}$ City and Residential Environment Renewal Development Act $₫$, and since the change of urban planning is not considered in remodeling, there is no separate regulation on construction ratio or rental houses and it is related with whether the increase of the number of households is permitted and whether urban planning is affected, which leads to a big difference in the procedure of a project and in the conditions of a project permission and the contents are shown in Fig. 1 as follows.

The remodeling system is being repetitively changed since the revision of ${ }^{『}$ Enforcement Ordinance of Construction Law』.

2) General remodeling is defined at No.10 (Definition) Article 2 of Construction Law and remodeling of apartment houses is defined at No.15 (Definition) Article 2 of Housing Law

3) 2 Article 4 of Enforcement Ordinance of Hosing Law 
Table 1. Statistics of remodeling business (Sep. 30, 2010 data)

\begin{tabular}{c|c|c}
\hline Project phase & $\begin{array}{c}\text { No. of total } \\
\text { complex }\end{array}$ & $\begin{array}{c}\text { No. of complex } \\
\text { located in Seoul }\end{array}$ \\
\hline Establishment of action plan & 41 & 30 \\
\hline $\begin{array}{c}\text { Selection of constructor and } \\
\text { completion of architectural review }\end{array}$ & 23 & 15 \\
\hline Development permit acquired & 7 & 7 \\
\hline Starting construction or completion & 9 & 6 \\
\hline
\end{tabular}

Source : data acquisition from the Ministry of Land, Transport and Maritime Affairs

There is an aspect that is progressed as a method to cope with the needs of the times rather than continuos system improvement that is progressed with comprehensive purpose related to remodeling system. However, since the term of 'remodeling' is introduced in 2001, 'remodeling district' was newly established in 2003 to designate the special district to ease the standard of construction and urban planning, and remodeling and the retention of the existing buildings were encouraged by an exception upon renewal projects. The exemption standard of value added tax of remodeling projects was established to financially support the system in 2004. The area limit of expansion that never existed before was created so there is an aspect that the ratio of expansion parts is monolithic but the piloti structure was approved and the flexibility of a plan was acknowledged within the scope that the overload is not imposed on a structure by permitting the expansion of upper part of the top floor. In 2006, in the case of expansion less than $30 \%$ of the scale of the existing national housing, value added tax was exempted so that the financial support was extended. In 2007, the construction term possible for renovation was reduced from 20 years into 15 years, which was limited to only apartment houses. Thus it seems that the law was revised toward the direction to revitalize the renovation but the actually completed cases were only 9 cases $^{4}$ ) as of September 2010 and the current promotion status is shown in Table 1.

However, it is considered that it's necessary to make it clear the direction of government policy and to cope with the demand of renovation of apartment houses that will be dramatically increased in the future with a long-term plan at the current point of time when 20 years passed since the first stage new town was formed in 1989.

\subsection{Operational Status of Remodeling System of Apartment Houses In and Outside the Country}

Generally, there is a correlation between the economic level of a country and the degree of revitalization of renovation. Based on the year of 1997, the average ratio that renovation takes up in the

4) Statistics of Remodeling Business, Written with reference of data from the Ministry of Land, Transport and Maritime Affairs as of Sep. 30, 2010 total construction market of 15 main countries in Europe was around $35 \%$, some $46 \%$ for Italy, some $43 \%$ for France and England, some 39\% for Denmark and Sweden, which showed that the developed countries had higher ratio than the average (Kim, 2002) but it was reported that the status of the country didn't reach even 10\% as of 2009 (Agenda of 46th Euroconstruct Conference, 1998). There is a tendency that the higher GDP of a country is, the bigger scale the renovation market has and it is recognized that the phenomenon that the scale of renovation market is getting bigger implies that the focus of housing policy is shifting from "supply of housing" to "housing management".

The renovation method that is used by developed countries is that the structure is retained as much as possible and its performance is improved so as not to give inconvenience to residents, whereas the renovation implemented in the country is close to reconstruction is to expand the area within a household and the public area and to change drastically the appearance of a building through the large-scaled expansion as well as to replace or to add the internal facilities. Therefore, the renovation in the country involving large-scaled demolition, moving and expansion can't make use of the original purpose as a sustainable construction method and causes the discharge of construction wastes in a large amount, which is a factor of environmental burden, and it could rather shorten the physical life of a structure so it came to result in confusion of a concept of renovation.

The developed countries support renovation with a purpose of extending the life of apartment houses and reducing the consumption of energy, especially encourage renovation including facilities for the disabled or old people by granting various benefits. For example, in France, the deteriorated complex is designated as 'bad complex' and a project is promoted for improving the residential environment of the whole complex and $20 \sim 30 \%$ of the total construction cost is supported for low-income residents as 'Housing Improvement Subsidy ( $\left.\mathrm{PAH}^{5}\right)$ ). However, by regulations, renovation must be implemented toward reducing the consumption of energy of a building and accompany the installation of facilities for the disabled within the complex. In case of Germany, there is various system of tax break and deduction of tax, which is that the tax corresponding to $10 \%$ of the total construction cost is deducted for $2 \sim 5$ years or the tax is deducted by converting the construction cost into installment over 40 years. And in the case of renovation with energy-saving type including installation of solar energy system, boiling facilities, heat pump and so on, $10 \%$ of installation cost of related facilities is deducted from an annual income tax for 10 years.

As above, the support system for renovation can be largely divided into subsidy, a loan, deduction of tax but is generally operated by mixing more than two systems.

5) PAH: Prêt à l'amélioration de l'habitat 


\section{Review on Validity of Expansion of Households in Remodeling of Apartment Houses}

For the expansion of households required in the aspect of raising business value of renovation of apartment houses, the possibility of institutional acceptance was diversely reviewed in the aspect of changes of population structure, architectural planning, urban environment, structural safety and fairness of a system.

\subsection{Aspect of Changes of Population and Social Structure}

Viewed from the aspect of changes in population structure, there is a tendency that the number of households for $1 \sim 2$ persons continuously and sharply increases. The average number of household member was sharply reduced like 2.88 persons in 2005 compared to 4.55 persons in 1980 s, which can be expected that the scale of required housing will be also reduced. The transition of the average number of household member is shown in Table 2.

This result implies that the traditional concept comprised of a couple and their children comes to be weakened and according to Table 3, the number of household having $1 \sim 2$ persons is expected to sharply increase. Therefore, since the demand of small-scaled apartment houses continuously increases, it is considered that it's not desirable to promote indiscreet renovation of expansion in pursuit of the rise of assets value through the expansion of area and household without considering the change of demand.

Table 2. Transition of average household member (unit: person)

\begin{tabular}{c|c|c|c|c|c|c}
\hline Classification & 1980 & 1985 & 1990 & 1995 & 2000 & 2005 \\
\hline Whole Country & 4.55 & 4.09 & 3.71 & 3.34 & 3.12 & 2.88 \\
\hline
\end{tabular}

Source: Reorganized by reference of Total Survey of Population \& Houses (1980 2005), the National Statistics Office

Table 3. Transition of changes in the number of household member

\begin{tabular}{c|c|c|c|c|c|c}
\hline Classification & 1980 & 1990 & 2000 & 2010 & 2020 & 2030 \\
\hline $\begin{array}{c}\text { Whole } \\
\text { Households }\end{array}$ & 7,969 & 11,355 & 14,312 & 17,152 & $\begin{array}{c}19,012 \\
(100 \%)\end{array}$ & $\begin{array}{c}19,871 \\
(100 \%)\end{array}$ \\
\hline 1person & 383 & 1,021 & 2,224 & 3,473 & $\begin{array}{c}4,109 \\
(21.61 \%)\end{array}$ & $\begin{array}{c}4,713 \\
(23.72 \%)\end{array}$ \\
\hline 2persons & 840 & 1,566 & 2,731 & 3,958 & $\begin{array}{c}4,844 \\
(25.48 \%)\end{array}$ & $\begin{array}{c}5,583 \\
(28.10 \%)\end{array}$ \\
\hline 3persons & 1,153 & 2,163 & 2,987 & 3,595 & $\begin{array}{c}3,866 \\
(20.33 \%)\end{array}$ & $\begin{array}{c}3,797 \\
(19.11 \%)\end{array}$ \\
\hline 4persons & 1,620 & 3,351 & 4,447 & 4,564 & $\begin{array}{c}4,746 \\
(24.96 \%)\end{array}$ & $\begin{array}{c}4,519 \\
(22.74 \%)\end{array}$ \\
\hline $\begin{array}{c}\text { More than } \\
\text { 5persons }\end{array}$ & 3,974 & 3,253 & 1,922 & 1,562 & $\begin{array}{c}1,446 \\
(7.61 \%)\end{array}$ & $\begin{array}{c}1,260 \\
(6.34 \%)\end{array}$ \\
\hline
\end{tabular}

Source: Reorganized by reference of Total Surveyed Households (1980 2000), Estimation of Future Households (2007) the National Statistical Office

\subsection{Aspect of Architectural Planning and Urban Environment}

Viewed from the architectural planning aspect of renovation, upon expansion for renovation, especially in the case of wall-type structure, since the plane plan and sunlight environment are poorly formed, consequently the residential environment may be deteriorated. Viewed from the actual cases of the complex formed, since the floor space index increased around 30\% more than one before renovation and much of the building-to-land ratio increased according to the current law that limits the vertical expansion, separated space from the surrounding blocks as well as outdoor space were narrowed. The renovation was started only in 9 complexes6) as of September 2010 and the overview is shown as Table 4.

Viewed from Fig. 2 for the changes of floor space index of relatively recently completed Su-Jung apartment or Pyung-Hwa apartment, since it increased $67 \%, 86 \%$ more than the existing complex respectively, the effect after completion on the surrounding regions as well as on the environment within the complex changed. On the other hand, since the reconstruction differs the layout flexibly like new construction and changes the number of floors without utilizing the existing structure, there are lots of variation in the complex and urban environment but there is less cases to concern with negative effects such as renovation. And since there's no regulation for relaxing the floor space index, some $10 \sim 20 \%$ in the number of households was increased within the scope of applying urban ordinance or international law and the degree of each change is shown as Table 5 .

To compare profits with reconstruction for the actual renovation projects, if it were reviewed with a premise that the number of households would increase $10 \%$, it is shown in Table 6 and it can be expected that the review on the effect on the residential environment after completion must be sufficiently

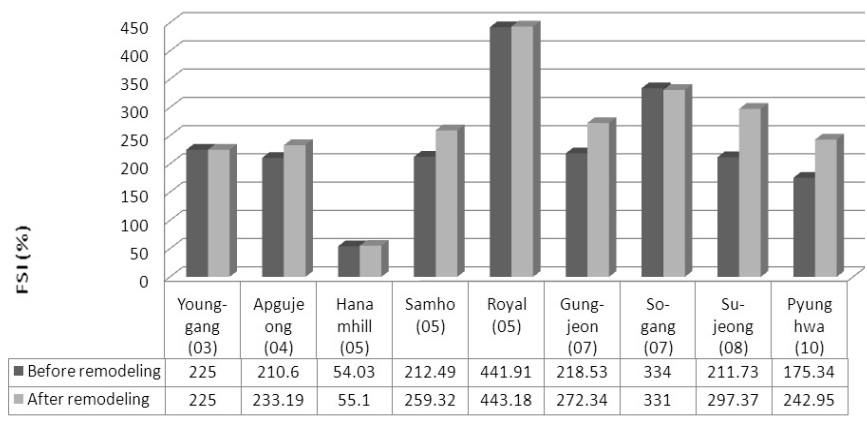

Fig. 2. Changes in Floor Space Index (FSI) after remodeling

6) Name of 9 complexes (region) : Yong Gang (Mapo), Seo Gang (Mapo), Royal Mansion (Yichon), Su Jung (Yichon), Gung Jun (Bangbae), Samho (Bangbae), Pyunghwa (Dangsan, completed in 2010), one in Busan, one in Gwangju, one in Gyungnam province 
Table 4. Changes in floor space index of complexes that renovation was completed (As of Sep. 30, 2010)

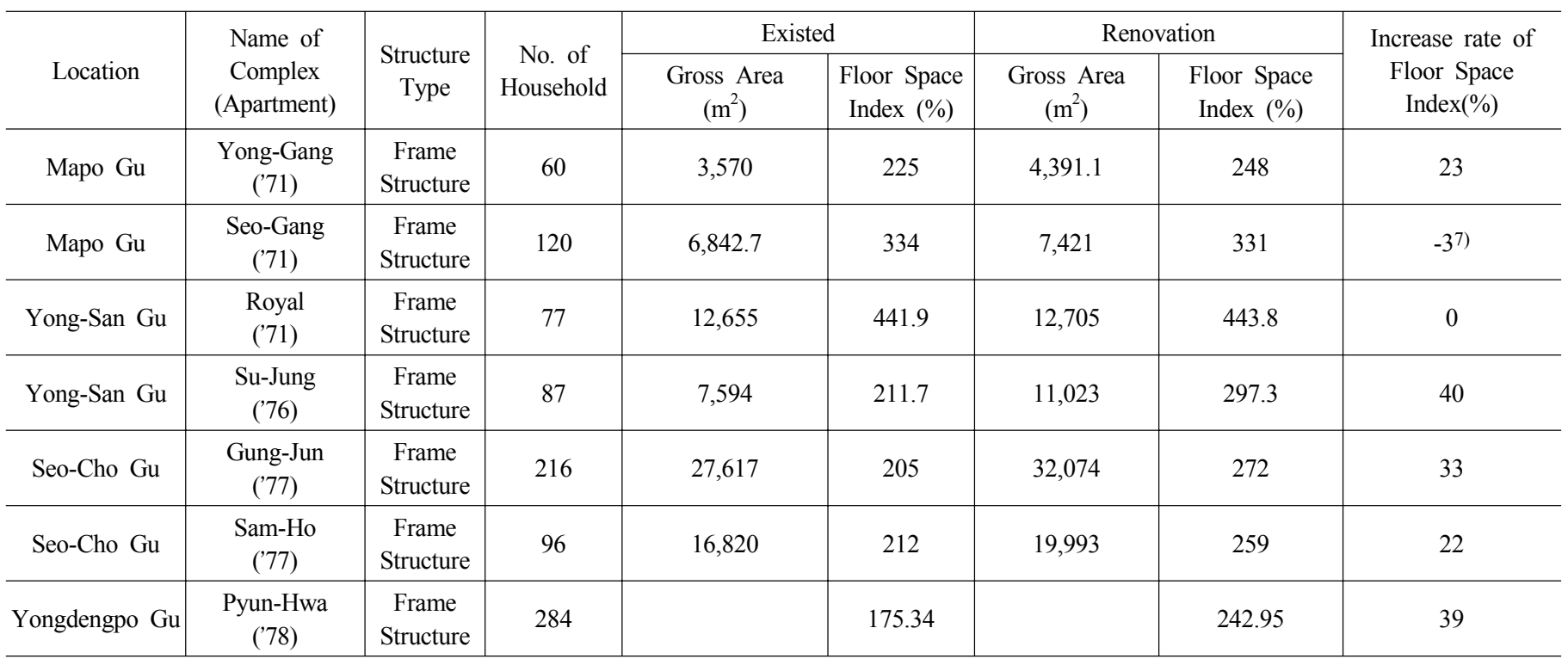

Table 5. Overview of complexes that reconstruction was completed in apartment houses

\begin{tabular}{|c|c|c|c|c|c|c|}
\hline \multirow[b]{2}{*}{ Location } & \multirow{2}{*}{$\begin{array}{l}\text { Name of complex } \\
\text { (Apartment) }\end{array}$} & \multicolumn{2}{|c|}{ Existed } & \multicolumn{2}{|c|}{ Reconstruction } & \multirow{2}{*}{$\begin{array}{l}\text { Increase rate of } \\
\text { households }(\%)\end{array}$} \\
\hline & & $\begin{array}{l}\text { No. of floor } \\
\text { (Floor) }\end{array}$ & $\begin{array}{c}\text { No. of households } \\
\text { (Household) }\end{array}$ & $\begin{array}{l}\text { No. of floor } \\
\text { (Floor) }\end{array}$ & $\begin{array}{c}\text { No. of households } \\
\text { (Household) }\end{array}$ & \\
\hline Mapogu & Yuwon sungsan & 10 & 290 & 25 & 320 & 10 \\
\hline Gang-dong-gu & Gil dong Jinheung & 10 & 770 & 25 & 800 & 4 \\
\hline Geum-cheon-gu & Nam Seoul Hanyang & 13 & 1,505 & 29 & 1,764 & 17 \\
\hline Eun-pyung-gu & Eunpyung & 15 & 360 & 15 & 400 & 11 \\
\hline Gang-dong-gu & Miju & 14 & 406 & 24 & 476 & 17 \\
\hline No-won-gu & Wolgye Dongshin & 12 & 864 & 25 & 956 & 11 \\
\hline Gang-dong-gu & Sindong-a & 12 & 972 & 29 & 1117 & 15 \\
\hline Gang-nam-gu & Nonhyun Gyungbuk & 14 & 308 & 30 & 366 & 19 \\
\hline Gang-nam-gu & Cheongsil & 12 & 1378 & 35 & 1603 & 16 \\
\hline
\end{tabular}

Table 6. Increase of Floor Space Index by remodeling

\begin{tabular}{|c|c|c|c|c|c|c|c|c|c|}
\hline \multirow[b]{2}{*}{$\begin{array}{l}\text { Name of } \\
\text { complex }\end{array}$} & \multirow[b]{2}{*}{$\begin{array}{l}\text { Type } \\
\text { (Area) }\end{array}$} & \multicolumn{3}{|c|}{ No. of households } & \multicolumn{4}{|c|}{ Floor space index $(\%)$} & \multirow[b]{2}{*}{ Remarks } \\
\hline & & Existed & $\begin{array}{c}10 \% \\
\text { Applied }\end{array}$ & Increment & Existed & $\begin{array}{l}30 \% \text { increase in } \\
\text { expansion area of } \\
\text { remodeling }\end{array}$ & $10 \%$ Applied & Increment & \\
\hline Seoul A & $\begin{array}{l}\text { 43Pyeong* type } \\
\text { (31Pyeong type) }\end{array}$ & 448 & 492 & 44 & 178 & 247.30 & 271.0 & 93 & \begin{tabular}{|c|} 
Completed \\
38households , 265\%
\end{tabular} \\
\hline \multirow{4}{*}{ Seoul B } & $\begin{array}{l}\text { 29Pyeong type } \\
\text { (22Pyeong type) }\end{array}$ & 26 & 26 & - & \multirow{3}{*}{239.6} & \multirow{3}{*}{313.52} & \multirow{3}{*}{348.3} & \multirow{3}{*}{108.7} & \multirow{2}{*}{$\begin{array}{l}\text { Piloti corresponding } \\
\text { to a complex with } \\
\text { Pyeong type of } \\
\text { increased } \\
\text { households }+ \\
\text { general sales of the } \\
\text { top floor } \\
\text { (Total 2floors expanded) }\end{array}$} \\
\hline & $\begin{array}{l}\text { 32Pyeong type } \\
\text { (25Pyeong type) }\end{array}$ & 130 & 130 & - & & & & & \\
\hline & $\begin{array}{l}\text { 43Pyeong type } \\
\text { (31Pyeong type) }\end{array}$ & 254 & 295 & 41 & & & & & \\
\hline & Sub total & 410 & 451 & 41 & & & & & \\
\hline
\end{tabular}

* Pyeong: a unit of measurement in Korea equal to $400 / 121$ square metres (3.3058 $\mathrm{m}^{2}, 3.954 \mathrm{sq}$ yd or $\left.35.586 \mathrm{sq} \mathrm{ft}\right)$ (refer to http://en.wikipedia.org). 
Table 7. Comparison between the standard of district unit plan and the actual floor space index (3rd class general residential region of first new town)

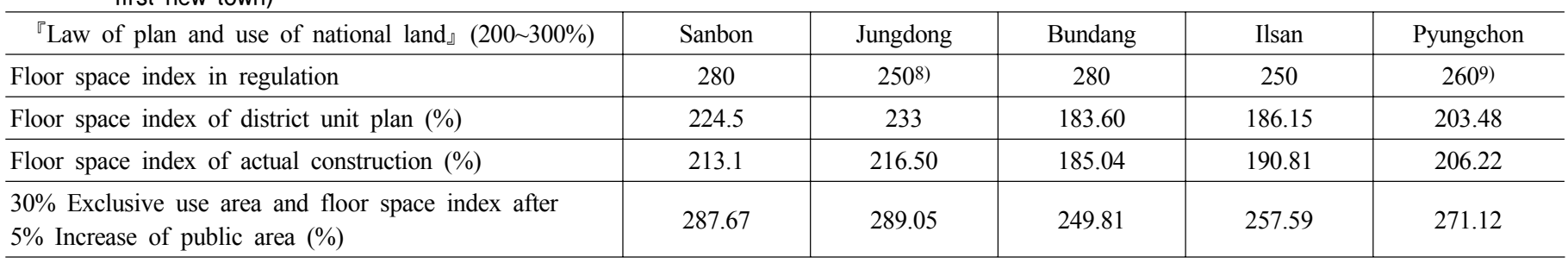

From : web site of Ministry of Government Legislation www.law.go.kr

Table 8. Change of floor space index after remodeling in 3rd class general residential region of first new town

\begin{tabular}{|c|c|c|c|c|c|}
\hline Classification & Sanbon & Jungdong & Bundang & Ilsan & Pyungchon \\
\hline Exceeding $300 \%$ of floor space index (No.) & 0 & 0 & 1 & 3 & 0 \\
\hline Exceeding rate of regulation standard (\%) & 75 & 96.88 & 2.5 & 39.44 & 82.98 \\
\hline
\end{tabular}

done and if the upper limit is not set up like reconstruction, there would be a big difference in the density of the surrounding residential areas.

This changes in floor space index due to renovation can extensively affect from the first new town in which most complexes were the subject of renovation because the whole city was formed almost at the same time to the whole city. With this problem, the first new town itself must review the establishment of the proper standard for renovation and if the changes of floor space index is reviewed with a premise of the floor space index at the time of construction and expansion renovation of exclusively using area of households which is $30 \%$ of the total complex with the subject of 3rd class general residential area that is in a compact with apartments, it is shown as Table 7 and if the relationship is looked into between floor space index of district unit plane and the actual floor space index distribution, it could be found that most complexes were formed by following the standard of district unit plan at the time of construction.

According to the expansion standard that is permitted by the current law, the increase of floor space index after renovation is some $30 \sim 40 \%$ and considering this situation, $30 \%$ expansion that is the permitted maximum for expansion of exclusive use area and the change of floor space index after renovation was predicted considering 5\% expansion of the public area, and the result is shown as Table 8 . Viewed from this result, since most complexes exceed the standard of urban planning regulation and high rank law, it was found that there are many cases that the standard of ' $30 \%$ ' that is permitted by the current law is not effective.

7) In the case of Sogang aparment in Mapo, area of land was changed: (Before change) $2,049 \mathrm{~m}^{2}$ (4lots) $\rightarrow$ (After change) $2,243 \mathrm{~m}^{2}$ (10lots) [reason of change] $\mathrm{SH}$ public corporation purchased governmentowned land nearby to expand forward and backward of a balcony

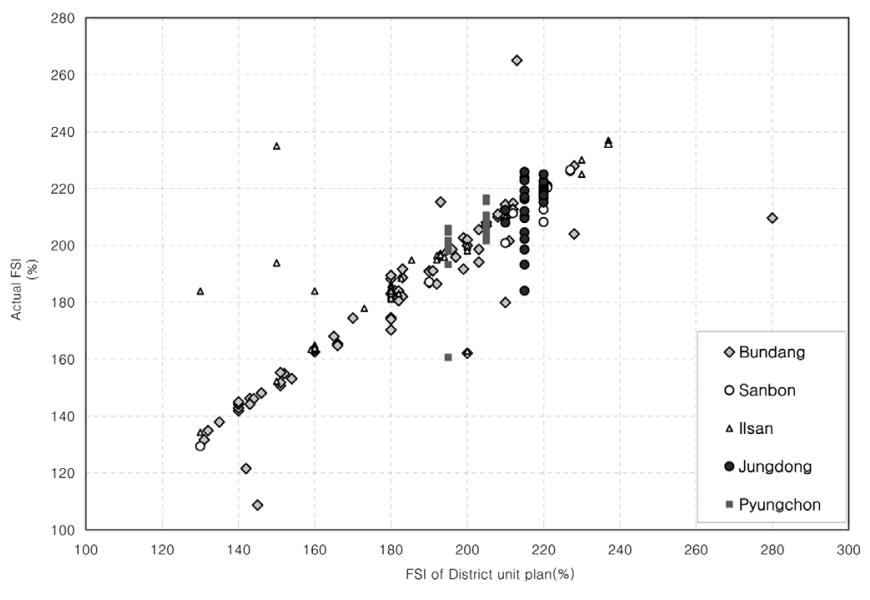

Fig. 3. Distribution of Floor Space Index (FSI) of district unit plan-actual Floor Space Index (FSI) in first new town

But it was found through the survey of opinions of persons' in charge that a local autonomous entity considered there was a problem in terms of management of urban density plan if floor space index is permitted considering urban environment. In the case of Seoul, there are quite a number of complexes exceeding the legal upper limit of floor space index such as $53 \%$ in 1 st Class general residential region, $42 \%$ in 2 nd Class general residential region and $27 \%$ in 3rd Class general residential region. ${ }^{10)}$

8) In the case of district unit plan, 300\% is applied, Jungdong new town corresponds to District Unit Plan Zone.

9) Housing Reconstruction Project according to "The Act of Urban and Residential Environment Renewal" and the remodeling according to 「Law of Housing」 is less than $280 \%$ and the remodeling of the existing apartment exceeding $280 \%$ of floor space index is less than the existing floor space index.

10) Refer to agenda provided by Ministry of Land, Transport and Maritime Affairs. 
Currently, the demand for $10 \%$ increase of the number of households for general sales is prevalent with the reason to reduce allotment of residents in terms of renovation. If this fact is additionally considered with the standard in the current law, as the case of A complex in Seoul is shown in Table 6, it could be expected that if the current density is $178 \%$, it would be increased up to $271 \%$ enough to be formed with a similar density with $280 \%$ that is the upper limit that is permitted in reconstruction. However, the average floor space index in 5 cities is more than $180 \%$ and it's obvious that if both remodeling expansion and the increase of the number of households are permitted, consequently it would have higher floor space index than a complex of reconstruction, and it is expected that it's actually impossible to permit this kind of remodeling project since people will concern about the congestion of cities.

\subsection{Aspect of Structural Safety}

Viewed from the aspect of structural safety, in the case of old apartment houses, there are many cases that there is no drawings so there is a limit to comprehend the performance of the existing structure, and since there is no preparation for the vertical expansion, if more than 2 floors are vertically extended, it could impose excessive burden on the foundations and vertical members and the actual situation is that the related standard and specification is not sufficient despite the complex connection-design for reinforcement and construction.

However, the difference exists in a point of view among experts about the structural safety and seismic capacity. The point of view of optimism is that once it is expanded, since the deteriorated structure could be reinforced, which kills two birds with one stone and the expansion of one floor would be possible to extend without a big increase of its own weight depending on design and finishing treatment. On the other hand, the point of view of pessimism is that the important thing is design and construction by precise safety inspection and performance evaluation but it's difficult to establish a plan to reinforce the structure since it's difficult to comprehend the status of the existing structure, which makes it difficult to permit the expansion.

Therefore, there is a unreasonable part to permit or prohibit equally all the situations with the system and it is required to improve the system so that it is possible for the more practical preparation or inspection.

First, when renovating apartment houses, it is considered that it would be possible to reject indiscreet demolition and large-scaled expansion and to make the demolition of major structural members restricted in terms of re-establishment of the concept of remodeling to recover the essence of renovation and possible to secure the safety of renovation and to reduce of financial burden

(Name of Conference: Conference for Persons in Charge of Local Autonomous Entities in the Metropolitan Area Related to District Unit Plan) would be possible. When demolishing for the remodeling of apartment houses, the demolition must be limited to the part for the connection and the demolition of parts that could cause damage in safety must be determined through review. Non-permission for the movement of columns and the shearing walls and prohibiting the integration of households if the wall between households is the shearing wall can guarantee the safety of structure.

And in the case of renovation accompanying expansion, to secure the safety of apartment houses that can be called as national assets from the disaster of earthquake so as to protect the life and property of the people, seismic reinforcement must be mandatory to reduce the risk level of the disaster of earthquake, apartment houses accompanying expansion must be included in the scope of checking safety against earthquake in 'Structural Safety Check' Article $32{ }^{『}$ Enforcement Ordinance of Construction Law $₫$. But an incentive is necessary for the part that an individual shares social costs for the improvement of seismic capacity so National Emergency Management Agency announced that the incentive system is being prepared such as reduction of local tax, a graded application of accident insurance rate when reinforcing earthquake-proof by remodeling according to ${ }^{\ulcorner}$Law of Earthquake Disaster Countermeasure」that came into effect in March, 2009.

It's subjective but it can be considered to operate 「Special Review Commission of Structural Design of remodeling」 to check the safety through the preliminary review of structural design of remodeling of apartment houses to cope with flexibly for each case. $\lceil$ Special Review Commission of Structural Design of Remodeling is operated by a delegated institute having an organization able to run a commission constantly such as Korea Infrastructure Safety \& Technology Corporation etc. and it must be operated in a way that a structural designer and council members jointly take responsibility to secure the effectiveness of review system. And in terms of Law of Housing, it must be regulated that $\ulcorner$ Professional Review of Structural Design of Remodeling」can be substituted with an architectural design review on Construction Law so it is necessary to consider a method to simplify the procedure of a project implementation while securing the safety of a structure.

\subsection{Aspect of Institutional Fairness with Reconstruction}

Finally, viewed from the aspect of fairness of the system, the remodeling receives supports of easing review of many kinds of restriction for revitalization of the system at the time of introduction and already affects urban environment due to permission of expansion of household area. In the case that the expansion of households is permitted for renovation, it's ruled out from the obligation of construction of rental houses and redemption of excess earnings that are applied to reconstruction, which is relatively advantageous condition so it's judged that there is a problem in the aspect of fairness with reconstruction. 
Table 9. Comparison of applied regulations between remodeling and reconstruction

\begin{tabular}{|c|c|c|}
\hline Classification & 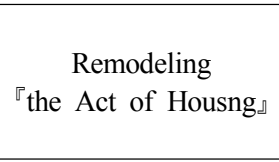 & $\begin{array}{c}\text { Reconstruction } \\
{ }^{\circledR} \text { the Act of Urban and } \\
\text { Residential Environment } \\
\text { Renewal } 』\end{array}$ \\
\hline $\begin{array}{l}\text { Definition of } \\
\text { terms }\end{array}$ & $\begin{array}{l}\text { Restraint of building } \\
\text { deterioration or } \\
\text { performance } \\
\text { improvement }\end{array}$ & $\begin{array}{l}\text { Residential environment } \\
\text { improvement in a region } \\
\text { that deteriorated bad } \\
\text { buildings cluster together }\end{array}$ \\
\hline $\begin{array}{c}\text { Building } \\
\text { construction } \\
\text { permit system }\end{array}$ & $\begin{array}{c}15 \sim 20 \text { years } \\
\text { ※ Safety inspection : } \\
\text { A D }\end{array}$ & $\begin{array}{c}30 \sim 40 \text { years } \\
\text { ※ Safety inspection : D, E }\end{array}$ \\
\hline $\begin{array}{l}\text { Construction } \\
\text { rate }\end{array}$ & Not regulated & $\begin{array}{l}\text { Less than } 85 \mathrm{~m}^{2}: 60 \% \\
\text { More than } 85 \mathrm{~m}^{2}: 40 \% \\
\text { (Less than } 60 \mathrm{~m}^{2} \text { in Seoul : } \\
20 \% \text { ) }\end{array}$ \\
\hline $\begin{array}{l}\text { Rental (small) } \\
\text { house }\end{array}$ & Not regulated & $\begin{array}{l}50 \% \text { of increased floor } \\
\text { space index is for the } \\
\text { construction of rental } \\
\text { houses }\left(60 \mathrm{~m}^{2}\right) \text { in restraint } \\
\text { area of overpopulation in } \\
\text { the Metropolitan area }\end{array}$ \\
\hline $\begin{array}{l}\text { Redemption of } \\
\text { excess earnings }\end{array}$ & Not regulated & $\begin{array}{l}\text { Redemption of excessive } \\
\text { earnings } \\
{ }^{『} \text { Act of redemption of } \\
\text { excessive earnings by } \\
\text { reconstruction } 』\end{array}$ \\
\hline Fund & $\begin{array}{l}\text { The remodeling with } \\
\text { a scale of national } \\
\text { housing is supported } \\
\text { by national housing } \\
\text { fund }\end{array}$ & Not regulated \\
\hline
\end{tabular}

Nevertheless, since the increase of the number of households is not permitted in renovation, in the case of renovation that there is no way to transfer earnings, there is a tendency for residents to prefer reconstruction to remodeling because they feel it's a big burden to share.

\subsection{Problems to be Considered Before Remodeling}

Likewise, it was diversely reviewed in the aspects of the changes of population and social structure, architectural planning, urban environment, structural safety, and fairness of the system for the demand of the increase of the number of households in remodeling of apartment houses, and the result is summarized as follows. First, viewed from in the aspect of the changes of population and social structure, since the promotion of remodeling to increase exclusive use area of households indiscreetly goes against the demand expected, it could not only cause difficulties in the trade of real estate but also lower asset value than expected. The congestion of cities is an important problem to be considered before revitalizing remodeling in the aspect of architectural planning and urban environment and it can cause many problems in urban environment as well as the environment of a complex because the basic residential environment such as sunlight, ventilation can be deteriorated. Since the aspect of structural safety may largely vary according to cases, it's difficult to regulate whether it's possible or not by law but it can be progressed by the judgment case by case through experts and it's reasonable to have possible conditions in advance. In the aspect of fairness of the system, since it receives the easing of many architectural planning conditions compared to reconstruction, it's relatively advantageous but the actual condition is that the preference for implementation of a project is a little low because the increase of the number of households that can create profits is not permitted.

\section{The Changes of Residential Environment According to Revitalization of Remodeling of Apartment Houses}

\subsection{The Direction of System Improvement for Revitalization of Remodeling of Apartment Houses}

Various physical types can be deduced depending on the features of the complex of apartment houses and the demand of residents from the remodeling to improve the performance of apartment houses. On the basis of expansion within $30 \%$ of exclusive use area, there can be various types from showing the performance that is next only to reconstruction such as the plane is changes and the underground parking lot is extended and to implement it without the change of appearance by improving performance through the minimum repair such as replacement of deteriorated facilities and the remodeling projects must be progressed by considering financial conditions of residents.

And it is necessary for the government to operate a system to induce or pull toward sustainable remodeling in the direction to reduce economical and environment loads. The major reason for permitting the increase of the number of households with high level of residents' demand is understood that a part of construction costs through sales can be applied to reduce the burden of residents. But as previously explained, there are expected problems in permitting floor space index that the number of households can be increased, or the vertical expansion. Therefore, if the possibility of application in the country through the cases of foreign financial support is reviewed, the direction of improving system can be prepared, for example, the project cost of remodeling is supported by a loan with low interest rate through national housing fund, the scope of exemption of value added tax on service fee of renovation is extended, an acquisition tax is imposed or deducted on the expansion part, the deduction of property tax when reinforcing earthquake-proof to prepare for the disaster of earthquake.

First, it is regulated that a loan is granted to an individual who intends to reconstructexpand or do major repair the deteriorated bad houses with items related with remodeling of apartment houses in $\ulcorner$ Regulation of Operation and Management of National 
Table 10. The Support system (plan) for remodeling projects cost of national housing fund

\begin{tabular}{l|l|c|c}
\hline \multicolumn{1}{c|}{ Type of fund } & Loan limit per household & Annual interest & Loan period \\
\hline $\begin{array}{l}\text { Project cost of housing } \\
\text { improvement }\end{array}$ & $80 \%$ of remodeling cost & $3.0 \%$ & $\begin{array}{l}\text { Deferred for one year with repayment } \\
\text { in 19years or deferred for 3years with } \\
\text { repayment in 17years3 }\end{array}$ \\
\hline $\begin{array}{l}\text { Extension cost of } \\
\text { subsidiary-welfare facilities }\end{array}$ & $\begin{array}{l}80 \% \text { of required cost of the } \\
\text { corresponding facilities }\end{array}$ & Same as above & Same as above \\
\hline $\begin{array}{l}\text { Cost for acknowledgment mark of } \\
\text { housing performance grade }\end{array}$ & $\begin{array}{l}100 \% \text { of required cost for the } \\
\text { corresponding grade field }\end{array}$ & Same as above & Same as above \\
\hline Support fund for carbon tax & $\begin{array}{l}100 \% \text { of evaluation fee of } \\
\text { framework recycling }\end{array}$ & Same as above & Same as above \\
\hline
\end{tabular}

Housing Fund $\lrcorner$ but loan conditions on current $\ulcorner$ Operational Plan of National Housing Fund $\_$can be eased to make it possible for the practical support for remodeling projects and various incentives such as supports for carbon tax depending on reduction of $\mathrm{CO}_{2}$ emission according to the cost acknowledging the house performance grade (including Green Home), the extension cost of subsidiary.welfare facilities and recycling of framework can be supported by National Housing Fund with low interest rate for a long term.

As shown in Table 10, it is reasonable to improve the system as the loan limit is to be up to $80 \%$ of remodeling cost per household for the items of housing improvement project etc. corresponding to remodeling on $\ulcorner$ Operational Plan of National Housing Fund $\lrcorner$ and the interest rate of a loan is also adjusted downwards to $3 \% \mathrm{~s}$ for annual rate as the same level in Berlin, Germany and make them pay back a loan in installments over 20 -year period.

It is necessary to make a plan for tax support on remodeling projects other than the easing of architectural regulations to revitalize remodeling by lowering self-allotment of residents. During remodeling, the deduction of tax is required and financial supports such as exclusion of application of the restriction regulation of Debt to Income (DTI) are also required for smooth supply of business funds. And currently when renovating apartment houses, an acquisition tax is considered as currently a new acquisition so it's imposed by the rate to the total construction cost but since it's reasonable to limit the tax for only the extended part, it can be suggested that an acquisition be imposed or deducted only for the extended part.

\subsection{The Changes of Residential Environment According to Revitalization of Remodeling}

Apartment houses constructed in a mass amount since 1970s in Seoul as well as currently the first stage new cities has passed 20 years and there is inconvenience because the space plan does not go well with the lifestyle here and now and outdoor environment was deteriorated, which is vulnerable to safety and many kinds of pipes are deteriorated so the demand for improvement of residential performance is a little too much. As an alternative to these, there are remodeling and reconstruction but both projects will increase floor space index after completion and it has shown the feature that projects that are advantageous for the increase of floor space index have been revitalized. Apartments completed early in 1980s have high demand of reconstruction due to their low density whereas apartments completed from mid and late 1980s to mid 1990s has poor business value due to their high density so they show a tendency that preference for remodeling increases. And 5 cities constructed as the first stage new cities belong to this and it is necessary to prepare for remodeling projects here and now.

Since a majority of deteriorated apartments are located at good position, it is necessary to improve residential and urban environment and rental houses for low-income class can't help being progressed as a residential welfare projects of the government. For example, the foreign renovation market such as Japan, Germany, England, France, America and Singapore etc. has the tendency of extending continuously, they pursuit two effects through this. they protect second-class people by offering tax and financial support for revitalization of remodeling and they utilize this as a residential welfare policy and reduce the consumption of energy in buildings with energy-saving houses and pursuit an effect to reduce $\mathrm{CO}_{2}$ emission. In the case of Japan, earthquakeproof performance is improved and they improve it into barrier-free space and pursuit the remodeling method to add new performance such as change of usage of a mansion into a house for old people, change of facilities like new construction of communication center, construction of information \& communication service, change of core type. And America, England, and Germany have the main reason to conduct renovation to raise energy efficiency of the existing buildings and to reduce the consumption of resources by recycling of structures and to reduce $\mathrm{CO}_{2}$ emission. The construction of sustainable environment is the globally common issue, not only an issue in the country and if a bond of sympathy is formed in a society for the importance of remodeling as a plan to reduce environmental pollution, it is judged that reconstruction has a limit in this aspect.

The remodeling currently has a tendency to be conducted in 
uniform remodeling method that needs to worry about the increase part of floor space index but as time goes by, if the meaning of remodeling is acknowledged in the aspects of environment-friendly or protection of second-class citizens, it is expected that remodeling projects in various types could be implemented.

There are many cases having a limit in expansion depending on the actual locational conditions and it is necessary to implement diversely remodeling with a reasonable method considering together the minimization of costs by regions, complexes.

For this, the system related with remodeling must be improved to make the flexible design possible and it is necessary for a local autonomous entity to make and manage a system considering the plan of the whole region.

\section{Conclusion}

The recent remodeling projects among apartment houses in South Korea have been completed with the shape similar to the reconstruction, and residents' burden by construction cost was increased due to this large-scaled expansion. That makes it hard to progress the remodeling of apartment houses.

It is expected that the demand of small housing will increase due to the tendency toward a reduction in the average number of household members and an increase of households with $1 \sim 2$ persons. In addition, the expansion of plane in a small apartment houses has a limit so it's desirable to implement remodeling considering the complex conditions and the demand of houses rather than implementing remodeling of indiscreet expansion of plane more than $30 \%$ of exclusive use area. Moreover, it is necessary to improve the remodeling process and regulation gradually so that the flexible housing design is possible according to the physical situation of neighborhood or residential condition.

There is the demand of residents to reduce the burden of remodeling construction cost through household sales by vertical expansion. However, it's difficult to look for similar cases in the developed countries that lay emphasis on preservation of the existing buildings. In addition, the extension to increase the number of households is difficult to be systematically allowed in the aspect of securing safety and fairness of the system with reconstruction.

To be a sustainable remodeling of apartment houses, it is necessary to progress remodeling in the direction of reducing economical, environmental loads here and now, and through this, it is considered that the essence of remodeling can be recovered. The government must induce the implementation of projects with recognizing the reducing effect of environmental loads that remodeling has. And, it must support business funds and prepare for a plan of tax support.

\section{References}

1. Kang, S. E. and Jun, Y. G. (2004), "Handbook of Remodeling of Apartment Houses", Research Forum of Korea Urban Development.

2. Ministry of Land, Transport and Maritime Affairs (2009), A Statement of Accounts of National Housing Fund.

3. Kim, S. S. (2002), "Perspective of Housing Remodeling Market and Countermeasures", LG Economic Researcher, Apr.: 23 24.

4. Kim, C. H., Park, G. B., Kwon, C. H., Im, S. H., "Long life Technology of Apartment Houses by Environment-Friendly Remodeling", Korea Infrastructure Safety \& Technology Corporation, Facility Safety.

5. Korea Land \& Housing Corporation, "Discussion of Remodeling Policy of Apartment Houses".

6. Korea Land \& Housing Corporation (2000), "Discussion of Remodeling f Apartment Houses: Plan for Revitalizing Remodeling Apartment Houses", Korea Institute of Construction Technology, Jan: $53 \sim 54$.

7. The Association of Remodeling of Apartment Houses in the Wide Metropolitan Area (2010), "Data on the Public Hearing of Legislation for Revision of Laws Related to remodeling".

8. Bong, I. S. (2009), "Empirical Approach to Interrelation between Housing Type and Density/Case Comparison between Gyunggi Province and Ile de France", Collection of Dissertation (Planning Dept.), Architectural Institute of Korea, 25(09).

9. Korea Land \& Housing Corporation (2003), "Remodeling of Apartments Houses For the First Time In the Country: remodeling Site of Model Apartment in Mapo Yong-gang", Remodeling Dept. of Urban Development Agency.

10. Julino, B. (2007), Apartment Republic, Humanitas p 35.

11. Bae, J. S. (2000), "Building Remodeling Emerging as Promising Projects", LG Weely Economy, LG Economic Researcher.

12. Ministry of Land, Infrastructure, Transport and Tourism of Japan (2004), "Manual for Renewal Mechanism of Mansion by Recycling Water", 6.

13. Choi, D. S. (2004), Architectural Remodeling for professional, Gumiseogwan, p. 205.

14. National Statistics Office (1980 2005), Total Survey of Population and Housing .

15. National Statistics Officen (2007), Estimation of Future Households.

16. National Statistics Office (1980 2000), Total Households Surveyed. 